\title{
Kinetics of TL Glow Peak of Limestone from Patharia of CG Basin (India)
}

\section{*Vikas Dubey, Suryanarayana N.S., Jagjeet Kaur}

Department of Physics, Govt. Vishwanath Yadav Tamaskar Post Graduate Autonomous College, DURG (C.G), 491001, India

*Corresponding Author: jsvikasdubey@gmail.com

\begin{abstract}
Behavior displayed by a thermoluminescence (TL) glow peak as radiation dose increases in limestone of Patharia mines of Chhattisgarh in India \{ Location : Durg (dist.) Elevation 274 meters, E 81 $21^{\circ}$ ' 48' $N-21^{\circ} 23^{\prime} 40.5^{\prime \prime}$ way point 196\} have been reported. The glow curve of Limestone peak is observed at $306.1^{0} \mathrm{C} \&$ slightly shifting of peak is observed at low temperature side. The value of activation energy and order of kinetics for $306.1{ }^{\circ} \mathrm{C}$ peak suggest low fading \& high stability.
\end{abstract}

Keywords: Computerized glow curve deconvolution, Thermoluminescence, Kinetic Parameters.

\section{INTRODUCTION}

Thermoluminescence dosimetry is a field of recent origin which has proved to be special importance in the estimation of radiation doses. Special attention has been paid to the development of materials for TL dosimetry. Number of scientists have standardized many materials for TL dosimetry and investigated in detail the fact that if luminescent material satisfies certain minimum requirements (dosimetric properties), they can be used in radiation dose estimation in TLD.

Thermoluminescence (TL) is the emission of light observed during the heating of insulating or semiconductor materials, provided that they have been previously exposed to ionising radiation (McKeever 1985; Martini M. Meinnardi, 1997; Chen and McKeever, 1997) [8 - 10]. 
The irradiation may take place in the laboratory or a radiative environment. Another possibility, which is exploited in dating applications, is when a naturally occurring material is irradiated by the radiation field of its natural surrounding.

The exposure to radiation perturbs the initial stable configuration of the material and the heating allows the release of the accumulated energy. The existence of thermoluminescence is linked to the internal ordered structure of insulators, and to the presence of imperfection in its lattice. The process can be described, in a simplified way, recurring to the energy band representation of insulators and assuming the presence of two kinds of imperfection in the crystal, as shown in Fig. 1.

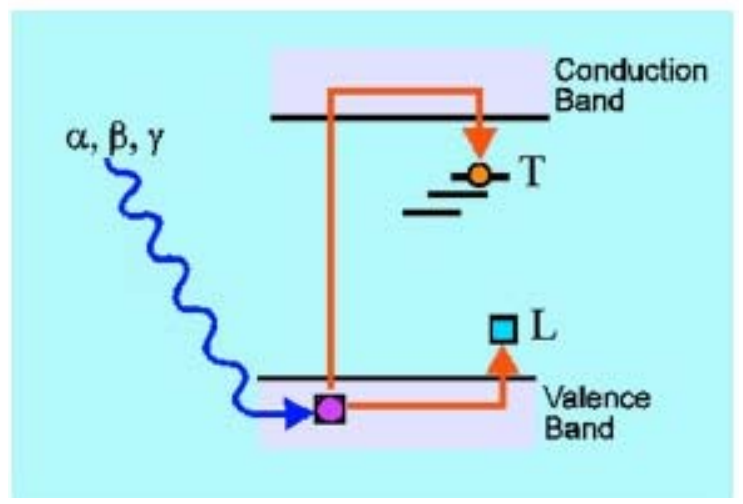

Fig. 1 Traps level in an insulating crystal

As a consequence of the exposure to ionising radiation, electrons and holes (vacancy of an electron) are produced in pairs: they can be captured in the electron and holes traps, whose energies are within the forbidden gap of the crystal. These traps are metastable, and usually their lifetime is very long at room temperature. The higher the exposure to ionising radiation, the higher number of electrons and holes trapped. In general, linearity is observed between the two quantities.

When the temperature of the crystal is increased, the carriers are raised energetically and freed from their traps to the conduction band from which they can recombine with a trapped electron or hole, thus emitting TL.

The curve representing the intensity of emitted light as a function of temperature is called glow curve, and its shape and intensity depend on the material and on the characteristic on the irradiation field, mainly the type and energy of radiation and its total amount (Fig. 2). 


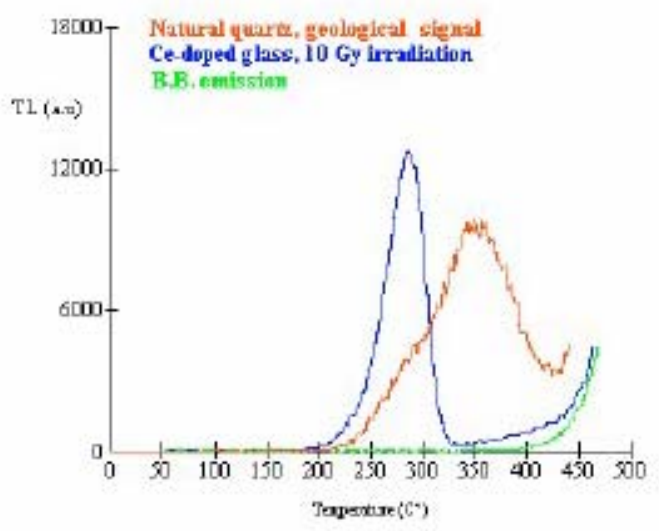

Figure 2. Examples of TL glow - curves

The study of the TL properties of a crystal is actually the study of the imperfections of its lattice, and TL is a very sensitive tool to detect imperfections even in very small quantities, and to understand the role played by defects and impurities in some physical properties of solids.

This last feature mentioned, i.e. its dependence on the amount of the energy absorbed during irradiation, called radiation dose, plays a primary role in the dosimetric applications of TL. Several artificial and naturally occurring materials show this favorable property, covering a very wide range of dose $\left(10^{-2}-10^{8} \mathrm{~Gy}\right.$ approximately). They are widely used in radiation protection practices and can be used to measure the doses due to occupational exposure and those accrued as a consequence of nuclear accidents. New materials have been developed to best fit the characteristics required by the main specific applications which are personnel, environmental, medical, retrospective and high - dose dosimetry (McKeever et al. 1995) [11].

Limestone is a very important \& wide spread sedimentary rock formed by chemical as well as organic processes. Pure limestone is composed of calcite i.e. calcium carbonate. But a few impure may contain other minerals such as quartz, feldspar, pyrite, clay etc.

C.G. basin limestone of Pathariya mines district Durg contain $\mathrm{Fe}_{2} \mathrm{O}_{3}-2.23 \%$, alumina $\left(\mathrm{Al}_{2} \mathrm{O}_{3}\right)-$ $1.47 \%$, calcium carbonate $\left(\mathrm{CaCO}_{3}\right)-35.30 \%$, magnesium oxide $(\mathrm{MgO})-12.20 \%$, silica $\left(\mathrm{SiO}_{2}\right)$ and LOI (Loss of Ignition) $-41.09 \%$.

Above percentage of components varies slightly from area to area. This lime stone are buff in colour. The source of calcite in these limestone is mostly endogenic i.e. the calcium carbonate has been derived from the rock itself due to dislocation of aragonite and high $\mathrm{Mg}$ - Calcite constituents. 
Sample of limestone is collected from Pathariya mines of district Durg Chhattisgarh. Fig.3 shows the Pathariya Limestone Mines. Irradiation is done by UV source of $365 \mathrm{~nm}$, the study of the TL glow curve of limestone has been done with different excitation time and the effect on the TL glow curve has been observed.

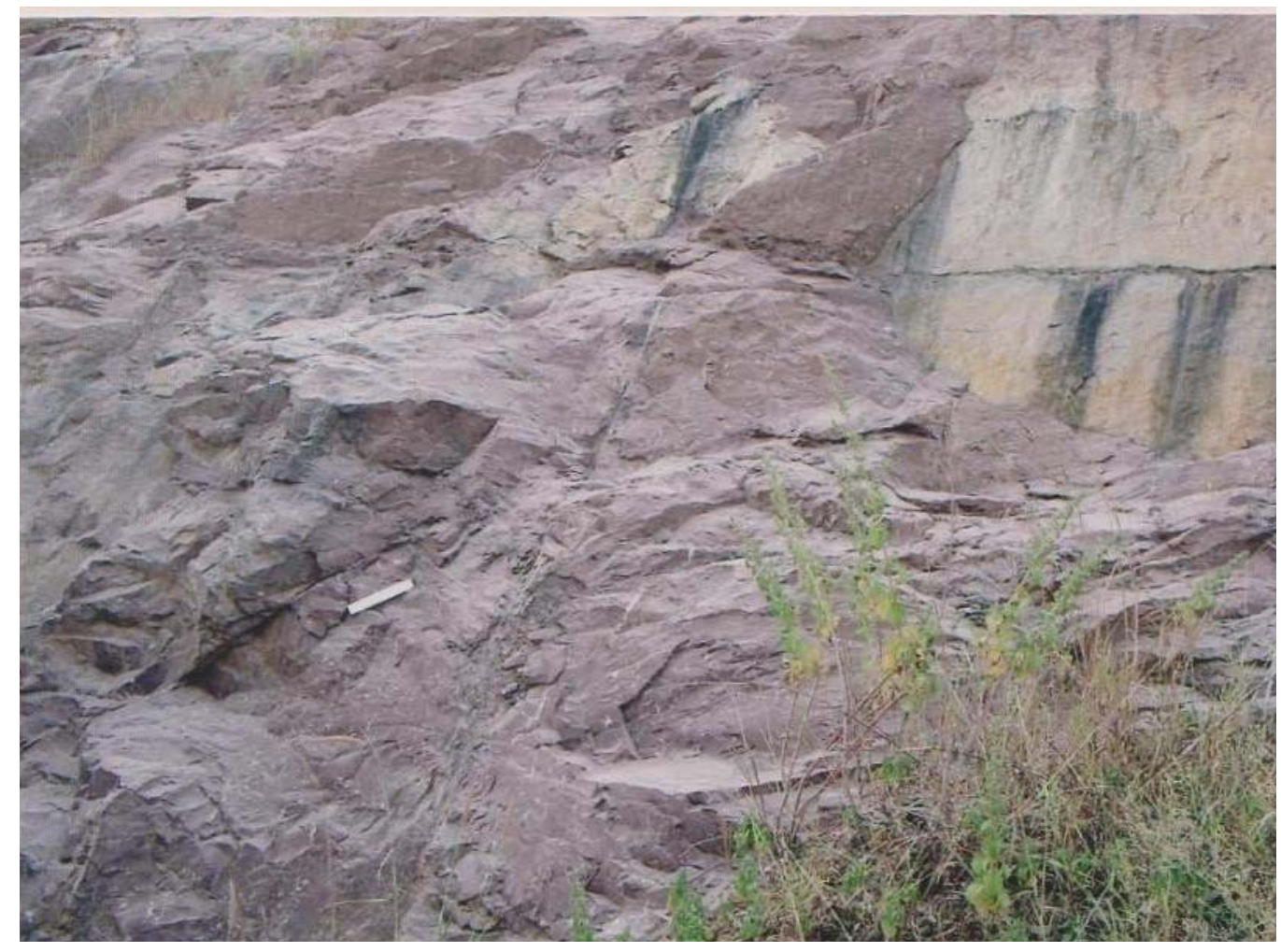

Figure 3. Pathariya Limestone Mines

Pathariya limestones are buff coloured cherty and contain calcite, aragonite, siderite, silica, felspars, clay minerals and minor amount of glauconite, pyrite etc. Of all these constituents, calcite and aragonite are most conspicuous. We give the UV exposure in crystal \& powder limestones with different time periods. The precipitation of calcium carbonate is aided by physicochemical, bacterial and algal decomposition. The early digenetic cement is made by breaking up of metastable carbonate minerals e.g. aragonite or by evaporation of pore water rich is carbonates. These limestones are thus the products of physiochemical processes, physical processes, biochemical and organic processes and are bound to show considerable mineralogical $\&$ chemical variations.

Chhattisgarh covers an area of 1, 35,084 sq.km. bounded by latitudes 17 47' and 24 50' North and longitudes 80 38' and 84 51' East. Fig. 4 shows the map of Chhattisgarh Pathariya Mines. 


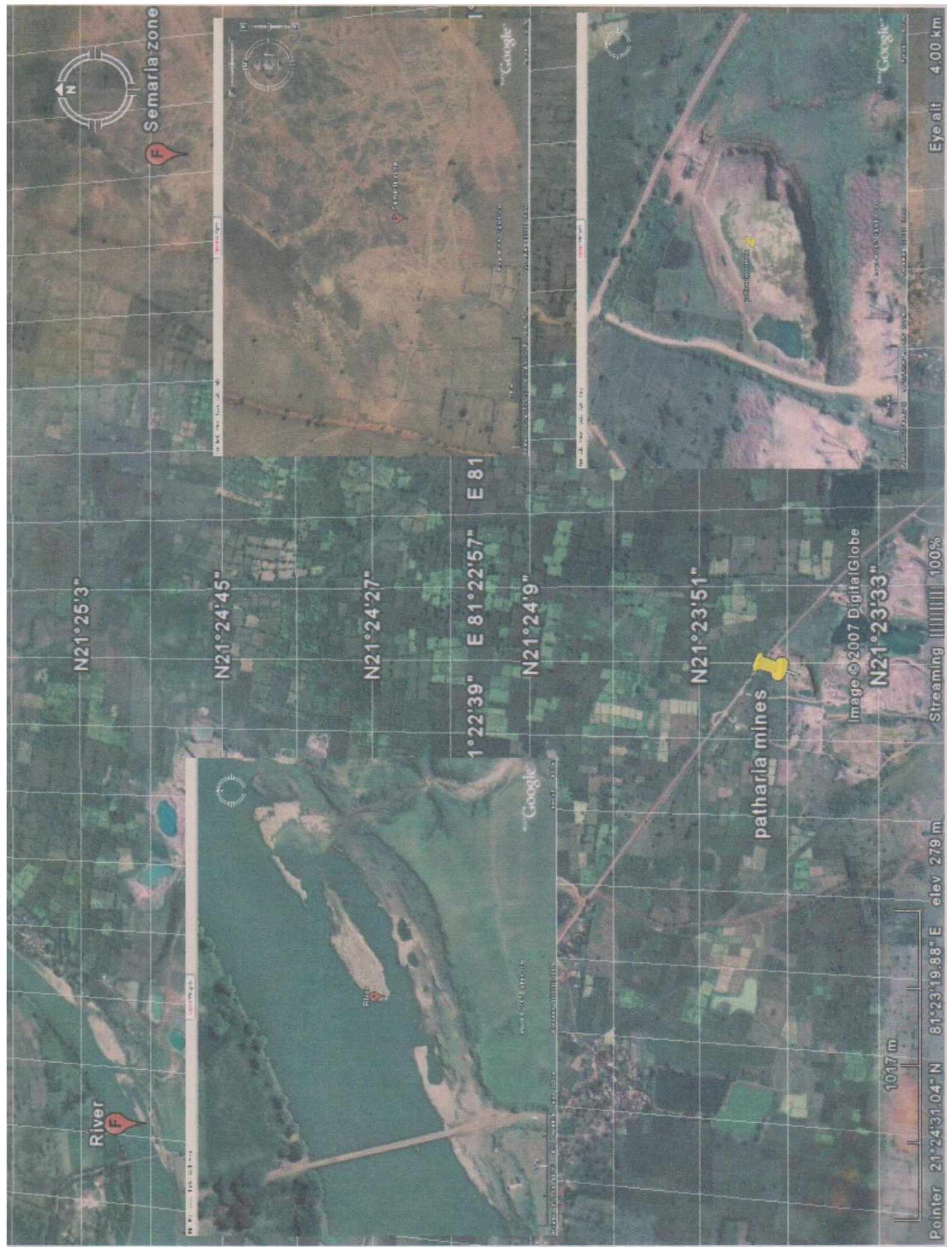

Figure 4. Map of Chhattisgarh Pathariya Mines 


\section{EXPERIMENT}

Samples of limestones were obtained from Patharia mines of Durg district of Chhattisgarh state (INDIA). TL measurements were taken from a TLD unit obtained from M/S Nuclionix Systems Hyderabad. During TL measurements heating rate used was $3.8^{\circ} \mathrm{C} / \mathrm{sec}$. UV $365 \mathrm{~nm}$ Source was used for irradiating the specimen. Every time $10 \mathrm{mg}$ weighed specimen is taken for TL measurement. From the data TL glow curves has been drawn using MS -Excel and the shape factor has been calculated.

\subsection{Detection of TL Signal}

The definition of TL itself suggests a rather easy way to detect it: what is needed is in fact an apparatus which allows heating the samples under controlled conditions, and an efficient light detection system. In most cases, the very low level of the emitted signal and the difficulties of controlling and measuring precisely the sample temperature require the use of complex and specifically designed systems. This is particularly true when TL intensity is very low, like in dating applications or when basic studies on defect centres are carried out.

In Fig.5 a schematic diagram of a TL measuring instrument is represented. Three main parts can be envisioned: the heating system, the detection system and the signal processing. The most common heating system is composed of a resistive planchet that heats up as a result of the passage of current through it. A common method of measuring the temperature is through the use of a thermocouple welded to the underside of the planchet. A photomultiplier tube (PMT) is normally used to detect the emitted TL.

In fact the efficiency of high - gain, very sensitive PMTs allow the detection of very low level signals with a convenient signal - to - noise ratio.

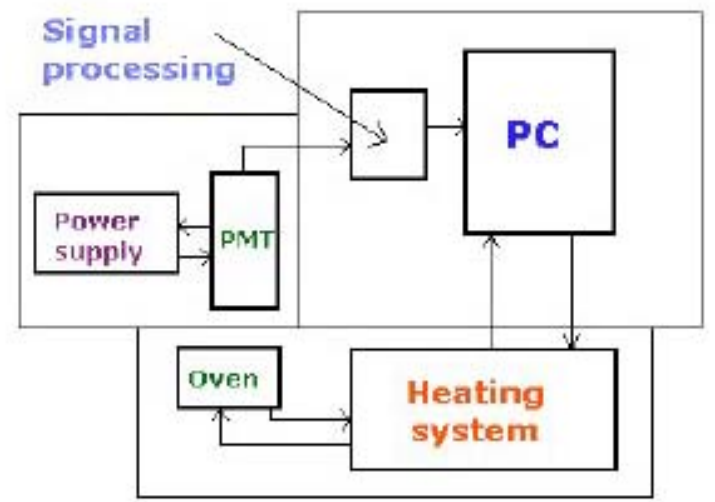

Figure 5. Diagram of a typical TL measuring system 
The recent development of high sensitivity light detectors, such as intensified diode arrays and Charge Coupled Devices (CCD), has allowed the measurement not only of the amount of emitted light, but also of its wavelength (Martini et al.1996) [12], obtaining information about the centres involved in the recombination processes. An example of such spectrum is reported in Fig. 6.

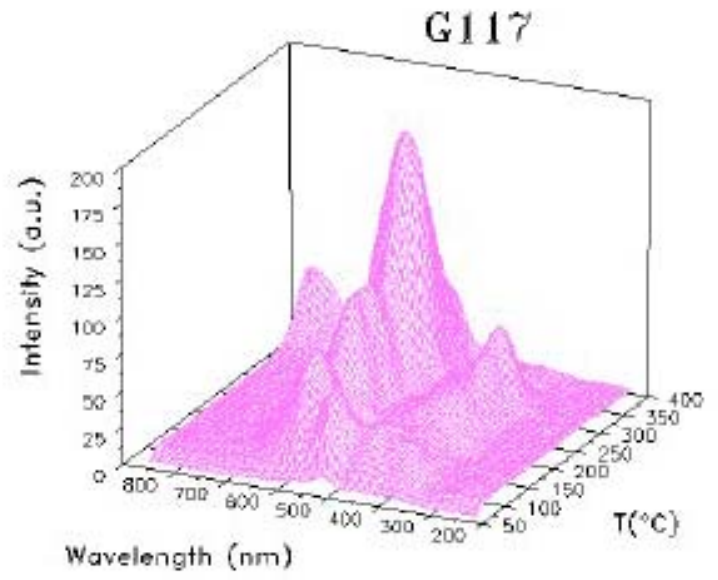

Figure 6. Ancient mosaic glass. Wavelength resolved TL spectrum

\section{RESULTS AND DISCUSSION}

The Thermoluminescence glow curve of the lime stone powder under study is shown in Fig. 7, 8, 9, 10 and 11 with different exposure time. From the TL studies it is found that with different UV exposure time a single glow peak is observed at $306.1^{\circ} \mathrm{C} \&$ slightly shifting of peak is observed in low temperature side. It has also been observed that TL intensity increases with time.

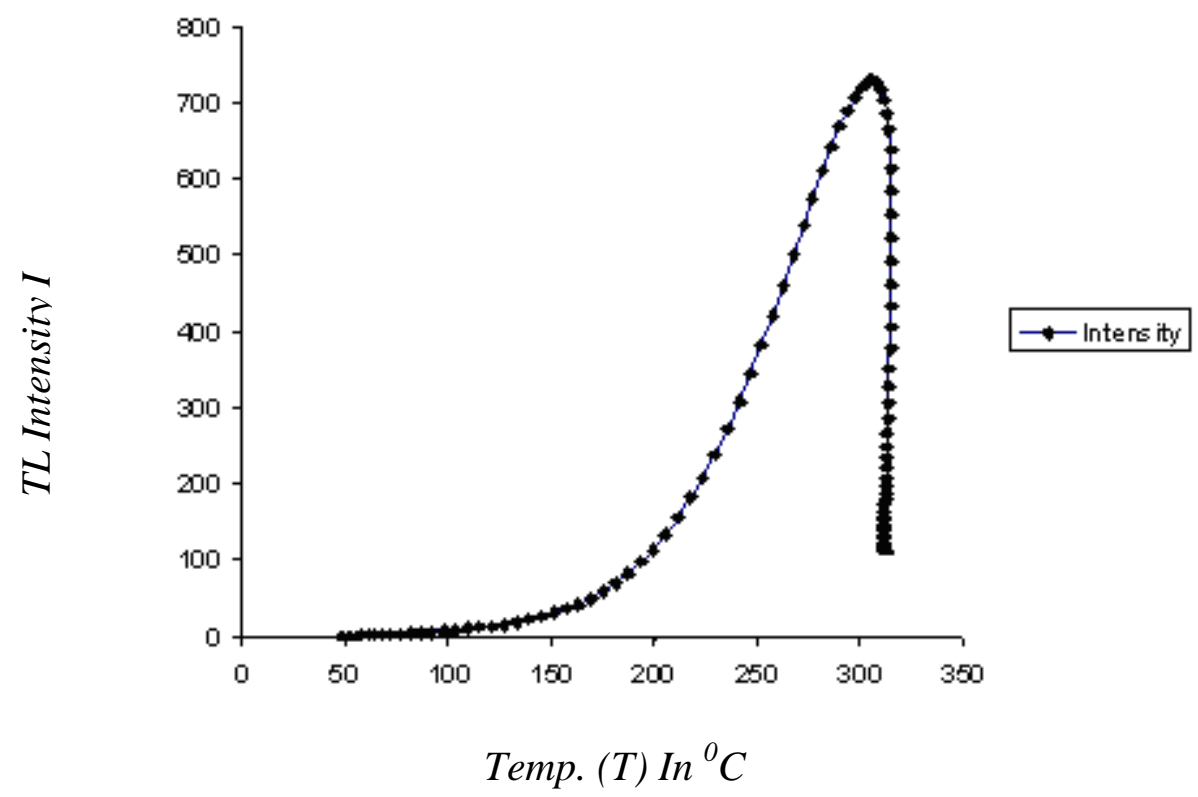

Fig. 7. Limestone powder exposure $10 \mathrm{~min}$. 
To analyze the observed TL curves the symmetry factor $(\mu)\left[\mu=\delta / \omega, \delta=T_{2}-T_{m}, \omega=T_{2}-T_{1}\right.$, $T_{m}$ being the peak temperature at the maximum, $T_{1}$ and $T_{2}$ are respectively, the temperatures on either side of $\mathrm{T}_{\mathrm{m}}$, corresponding to half intensity] is calculated [1]. The peak parameters (peak temperature, full widths, and shape factor) are shown in Table 1. The variation of shape factor $(\mu)$ implies that the first peaks is of first order kinetics. Since the shape factor is not unique for the intense peak one can speculate it as a consequence of overlapping of neighboring peaks.

\begin{tabular}{|c|c|c|c|c|c|c|c|c|}
\hline \multicolumn{9}{|c|}{$\begin{array}{c}\text { Table } 1 \text { - shape factors }(\mu) \text { of lime stone powder irradiated by UV exposure } 365 \mathrm{~nm} \\
\text { Source }\end{array}$} \\
\hline $\begin{array}{l}\exp \\
\text { time }\end{array}$ & $\mathrm{T}_{1}$ & $\mathrm{~T}_{\mathrm{m}}$ & $\mathrm{T}_{2}$ & $\mathrm{~T}_{\mathrm{m}} / 2$ & $\begin{array}{c}\tau=\left(\mathrm{T}_{\mathrm{m}}-\right. \\
\left.\mathrm{T}_{1}\right)\end{array}$ & $\begin{array}{c}\delta=\left(\mathrm{T}_{2}-\right. \\
\left.\mathrm{T}_{\mathrm{m}}\right)\end{array}$ & $\begin{array}{c}\omega=\left(\mathrm{T}_{2}-\right. \\
\left.\mathrm{T}_{1}\right)\end{array}$ & $\mu=\delta / \omega$ \\
\hline $10 \mathrm{~min}$ & 252.22 & 306.1 & 314.42 & 153.05 & 53.88 & 8.32 & 62.2 & 0.133762 \\
\hline $15 \mathrm{~min}$ & 252.62 & 305.37 & 313.24 & 152.685 & 52.75 & 7.87 & 60.62 & 0.129825 \\
\hline $25 \mathrm{~min}$ & 248.09 & 300.34 & 312.48 & 150.17 & 52.25 & 12.14 & 64.39 & 0.188539 \\
\hline $35 \mathrm{~min}$ & 246.23 & 299.57 & 312.01 & 149.785 & 53.34 & 12.44 & 65.78 & 0.189115 \\
\hline $50 \min$ & 246.13 & 298.62 & 313.75 & 149.31 & 52.49 & 15.13 & 67.62 & 0.22375 \\
\hline
\end{tabular}

Fig 7 to 11 represents the thermoluminescence (TL) glow curves of limestone. The chemical composition or the presence of $\mathrm{Fe}_{2} \mathrm{O}_{3}(2.23 \%)$ and clay minerals caused a drastic reduction in the TL light output with shifting of glow - peak positions towards lower temperature. This process inhibits the radiative recombination of electron and hole centres causing a reduction in the TL light output. The maximum quenching of TL light output of limestone containing 2.23 mol\% of $\mathrm{Fe}_{2} \mathrm{O}_{3}$ and clay minerals obviously suggests the presence of larger concentration of Calcium Carbonate $\left(\mathrm{CaCO}_{3}\right)-35.30 \%$, state in the limestone.

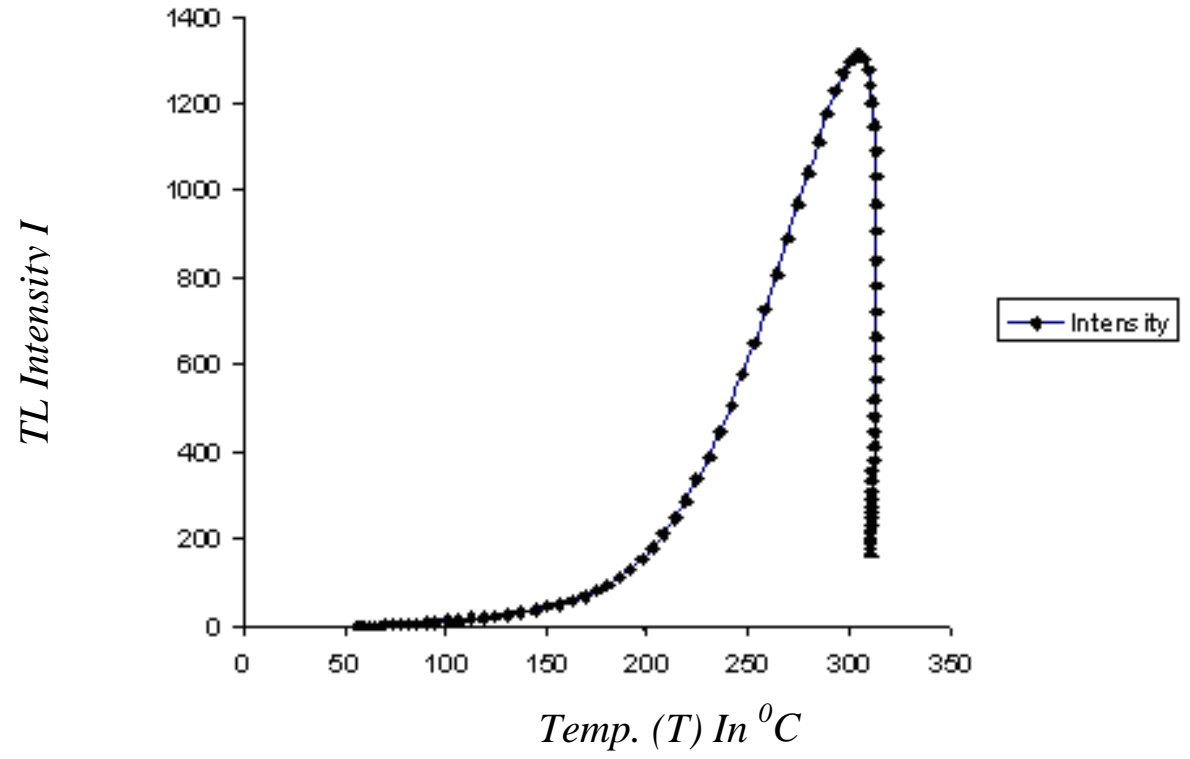

Fig.8. Limestone powder exposure 15 min. 
A TL study of the sample under consideration clearly shows a single glow peak which is due to maximum percentage of $\mathrm{CaCO}_{3}$.

If it is assumed that the higher temperature component of the peaks are lower in intensity at small doses but grow faster as the dose increases than the lower temperature components, then the net result will be a shift towards higher temperature. The decreases in the peak temperature at higher dose can be explained if it is further assumed that the higher temperature component saturate faster than the lower temperature components. Quantatively this means the lower temperature of peak position of high temp glow peak with increase in dose. Component begin to grow faster in intensity than the higher temperature component from the dose where saturation begins hence the observed decreases in peak temperature begins to decreases from the exposure time 25 min where saturation begins for this peak (Fig. 9). A similar argument has been used by Kitis et al (2005) [13] to explain a shift to lower.

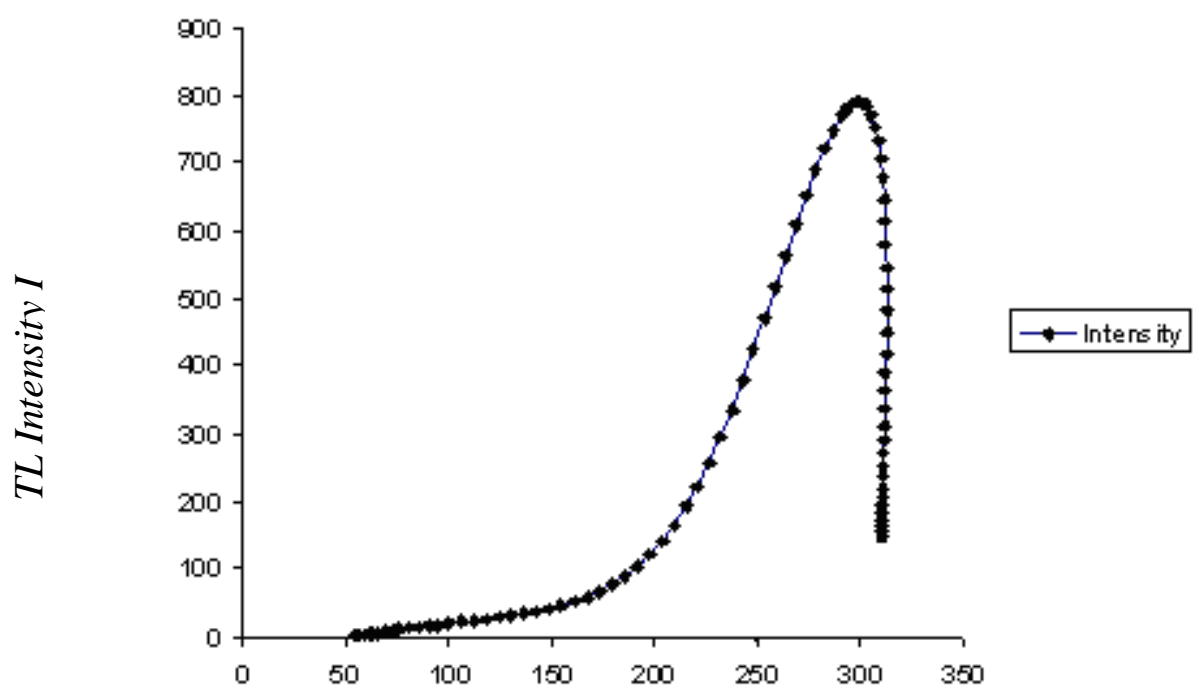

Temp. (T) In ${ }^{0} \mathrm{C}$

Fig.9. Limestone powder exposure 25 min. 


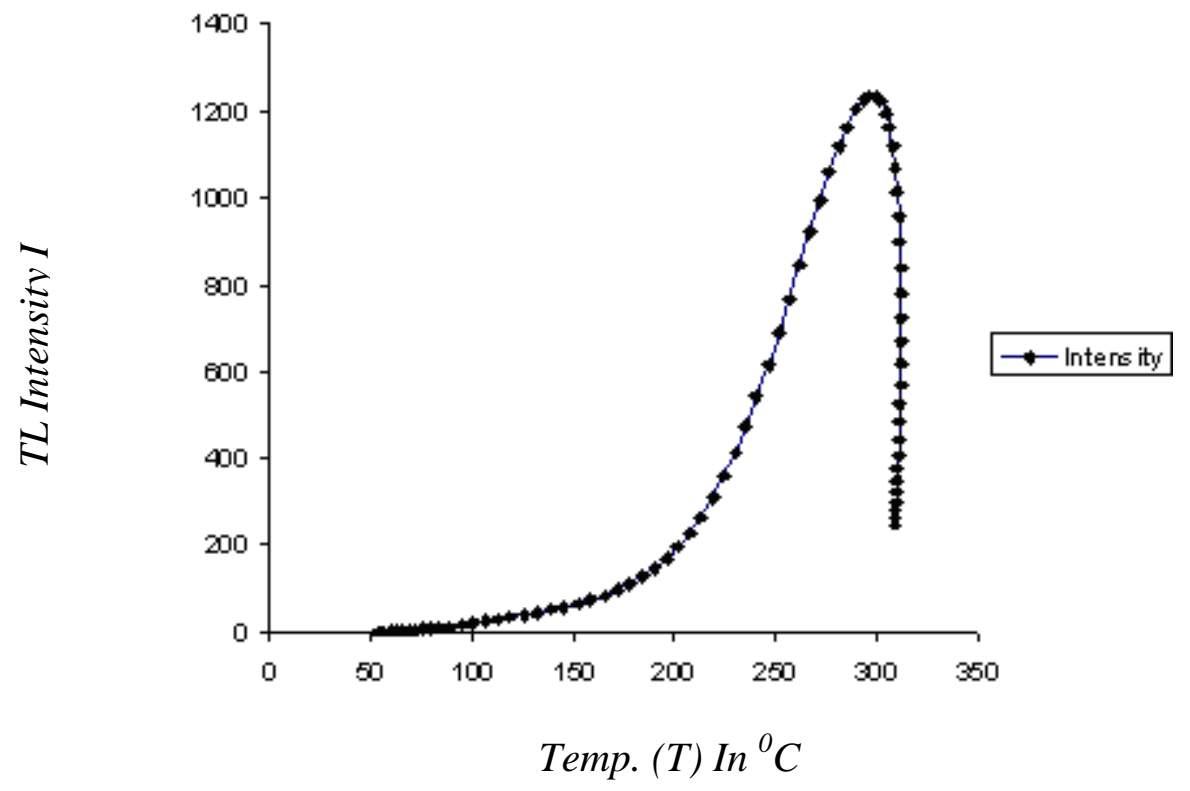

Fig.10. Limestone powder exposure $35 \mathrm{~min}$.

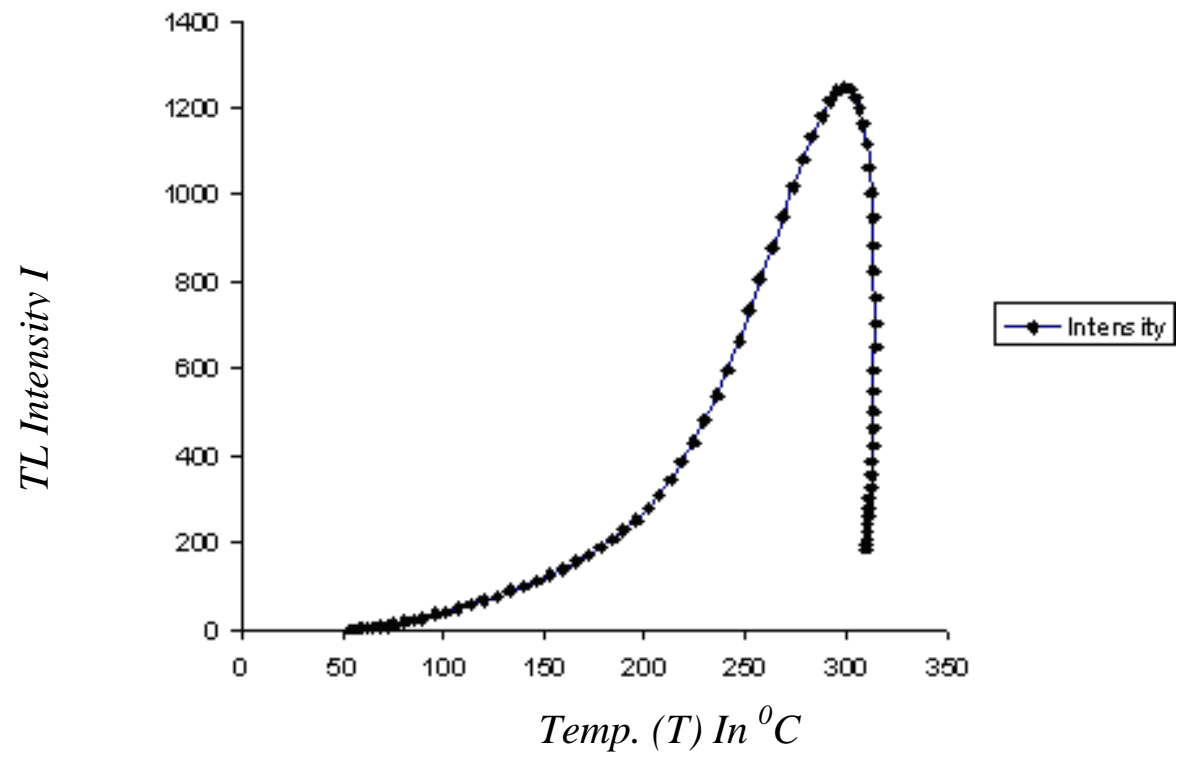

Fig.11. Limestone powder exposure $50 \mathrm{~min}$.

\section{ACKNOWLEDGEMENT}

We are grateful to UGC New Delhi for funding through a Major Research Project entitled "TL studies of limestone, calcite and Quartz available in Patharia, Samaria and Rasmada, Nandini and Kodwa areas in Durg district of Chhattisgarh- Characterization of Chemical Composition”. 


\section{REFERENCES}

[1] Chen R J, Electrochem Soc, 116 (1969) 1254.

[2] Ponnusamy V, Ramasamy V, Dheenathayalu M and Gopalakrishnan M, Indian J Phys, 78 A (2004) 327.

[3] Pagonis V and Michael C, Radiation Meas, 23 (1994) 131.

[4] Doredrajit S and Ingotombi S, J phys D: Appl Phys, 28 (1995) 1509.

[5] Krish Y, Townsend P D \& Soval S, Nucl Tracks Radiat Meas, 13 (1987) 115.

[6] Mambi K S V \& Mitra S, Thermochim Acta, 27 (1978) 61.

[7] Gartia R K, Singh S J \& Mazumdar P S, Phys Status Solidi a, 114 (1989) 407.

[8] McKeever S. W. S. (1985): Thermoluminescence of solids, Cambridge University Press, Cambridge, 390 pp.

[9] Martini M. and Meinardi F. (1997): Thermally stimulated luminescence: new Perspectives in the study of defects in solids, La Rivista del Nuovo Cimento 20-4 (8): 1-71.

[10] Chen R. and McKeever S.W.S. (1997): theory of Thermoluminescence and Related Phenomenon, World Scientific, Singapore, New Jersey, London, Hong Kong. 559 pp.

[11] McKeever S.W.S., Moscovitch M. and Townsend P.D. (1995): Thermoluminescence Dosimetry materials: Properties and Uses, Nuclear Technology Publishing, Ashford, 221 pp.

[12] Martini M., Paravisi S. and liguori C. (1996): A new high sensitivity spectrometer For 3D thermoluminescence analysis, Radiation Protection Dosimetry 66 (4): 47-51.

[13] Kitis et al, 2005 G.kitis, E.C. ZoragoZ and c.Furetta; appe.Radrat.sof.63 (2005) PP$247-254$ 